\title{
Inspiratory muscle strength is a determinant of maximum oxygen consumption in chronic heart
} failure

\author{
T P Chua, S D Anker, D Harrington, A J S Coats
}

\begin{abstract}
Objective-To investigate the significance of respiratory muscle weakness in chronic heart failure and its relation both to maximum oxygen consumption during cardiopulmonary exercise testing and to skeletal muscle (quadriceps) strength.
\end{abstract}

Subjects-Seven healthy men aged 54.9 (SEM 4.3) years and 20 men with chronic heart failure aged $61.4(1.6)$ years $(P=$ $0.20)$ with radionuclide left ventricular ejection fraction of $25 \cdot 4(3 \cdot 0) \%$.

Methods-Mouth pressures during maximum static inspiratory effort $\left(\boldsymbol{P}_{\operatorname{Imax}}\right)$ at functional residual capacity (FRC) and residual volume (RV) were measured in all subjects and taken as indices of inspiratory muscle strength. Similarly, mouth pressures during maximum static expiratory effort $\left(\boldsymbol{P}_{\text {Emax }}\right)$ at FRC and total lung capacity (TLC) were taken as indices of expiratory muscle strength. Cardiopulmonary exercise testing was performed in all subjects. All controls and 15 heart failure patients also had their right quadriceps muscle strength measured.

Results-There was respiratory muscle weakness in heart failure patients, with reduction of $P_{\operatorname{Imax}}$ at FRC $(59.7(6.3) v$ $\left.85.6(9.6) \mathrm{cm} \mathrm{H}_{2} \mathrm{O}, P=0.045\right), P_{E \max }$ at FRC (94.8 (6.2) $v 134.6(9.1) \mathrm{cm} \mathrm{H}_{2} \mathrm{O}, \mathrm{P}=$ $0.004)$, and $P_{E \max }$ at TLC $(121 \cdot 7(8 \cdot 5) v$ 160.7 (13) $\left.\mathrm{cm} \mathrm{H}_{2} \mathrm{O}, \mathbf{P}=0.028\right)$. $P_{\operatorname{Imax}}$ at $\mathrm{RV}$ was also reduced but this did not reach statistical significance $(77.3(6.6) v 89.3$ (13) $\left.\mathrm{cm} \mathrm{H}_{2} \mathrm{O}, \mathbf{P}=0.44\right)$. There was also significant weakness of the right quadriceps muscle $(308.5$ (22) $v 446.2$ (28) $N, P$ $=0.001)$. $P_{\text {Imax }}$ at both FRC and RV correlated with maximum oxygen consumption $(r=0.59, P=0.006$, and $r=0.45, P=$ 0.048 respectively) but not $P_{\text {Emax }}$. There was, however, no significant correlation between $\boldsymbol{P}_{\text {Imax }}$ and right quadriceps strength.

Conclusions-Respiratory muscle weakness is seen in chronic heart failure. The results suggest that inspiratory muscles are important in determining maximum oxygen consumption and exercise tolerance in these patients. The lack of correlation between respiratory and right quadriceps muscle strength further suggests that the magnitude and time course of respiratory and locomotor muscle weakness may differ in individual patients. Treatment aimed at improving the function of the involved muscle groups may alleviate symptoms.

\section{(Br Heart $\mathcal{F} 1995 ; 74: 381-385)$}

Keywords: chronic heart failure; respiratory muscles; maximum oxygen consumption; exercise tolerance

Respiratory muscle weakness has been reported in patients with chronic heart failure..$^{1-3}$ It has also been proposed that respiratory muscles may play an important role in causing breathlessness in this condition. ${ }^{45}$ There is a significant correlation between respiratory muscle weakness and the ratings of dyspnoea during daily activities ${ }^{2}$ as well as during exercise testing ${ }^{3}$ in these patients. Histological changes in the diaphragm have also been shown. ${ }^{6}$ The exact cause of respiratory muscle weakness is not known but it may be related to muscle underperfusion ${ }^{7}$ or may have a similar pathogenic basis to that of the skeletal muscle abnormalities often seen in these patients. ${ }^{8-10}$ Measurements of locomotor muscle function have indeed shown a reduction in maximum isometric force production of the quadriceps and its increased tendency to fatigue in chronic heart failure. ${ }^{11}$

Respiratory muscle function has not been widely studied in chronic heart failure. The objective of this study was therefore to investigate respiratory muscle strength in patients with heart failure and to examine its correlation with maximum oxygen consumption, an objective measurement of exercise capacity. Since the relationship between respiratory muscle strength and locomotor muscle strength is unknown, this was also assessed in our study.

\section{Methods}

Twenty male patients with chronic heart failure between 46 and 74 years of age (mean age 61.4 (SEM 1.6) years) participated in this study. Patients with known pulmonary disease were excluded since abnormal skeletal muscle metabolism may also be seen in patients with chronic lung disease. ${ }^{12}$ All patients had suffered from heart failure for more than three months and were adequately treated with diuretics. Mean multigated acquisition (MUGA) radionuclide left ventricular ejection fraction was $25 \cdot 4(3.0) \%$. Heart failure was caused by ischaemic heart disease in 13 patients, idiopathic dilated cardiomyopathy in six, and valvar heart disease in one. None of the patients was limited by angina. A control group of seven healthy men (mean age 54.9 (4.3) years, range $41-73$ years, $P=0 \cdot 20$ ) was also studied. None had respiratory symptoms. Subject characteristics, including the results of Cardiac Medicine, Royal

and Lung Institute

Dovehouse Street, London

Accepted for publication

30 May 1995 
of lung function tests, are summarised in table 1 . The study was approved by the local ethics committee and all subjects gave informed consent.

\section{RESPIRATORY MUSCLE STRENGTH}

Mouth pressures during maximum static inspiratory effort $\left(\mathrm{P}_{\text {Imax }}\right)$ at functional residual capacity (FRC) and residual volume (RV) and during maximum static expiratory effort $\left(P_{\text {Emax }}\right)$ at FRC and at total lung capacity (TLC) were measured. These were taken as indices of inspiratory and expiratory muscle strength respectively. ${ }^{13}$ All measurements were made with the subject standing and wearing a nose clip. Mouth pressures were measured in $\mathrm{cm} \mathrm{H}_{2} \mathrm{O}$ with a manufacturer calibrated pressure monitor (Druck) and were visually displayed on a liquid crystal display screen on the monitor. Subjects breathed through a pneumotachograph calibrated for spirometry (Innovision) with a scuba-type mouthpiece and coupled to a $\mathrm{T}$ valve. At the selected lung volume (FRC, RV, or TLC), the valve was turned to obstruct the airway so that the subject's mouth pressure during maximum inspiratory or expiratory effort could be measured with the pressure monitor. A small leak using a 22 gauge needle was incorporated in the airway to prevent glottic closure, and light pressure was applied to the cheeks during expiratory manoeuvres to minimise the contribution of facial muscles. Subjects were urged to perform maximally, and repeated efforts were made until the two highest values agreed within $\pm 5 \mathrm{~cm} \mathrm{H}_{2} \mathrm{O}$. An average of four efforts was usually required for each lung volume. Subjects were allowed to rest for a few minutes when necessary between the manoeuvres.

QUADRICEPS MUSCLE STRENGTH

All controls and 15 heart failure patients also

Table 1 Characteristics of normal subjects and patients with chronic heart failure $(C H F)$. Values are means (SEM)

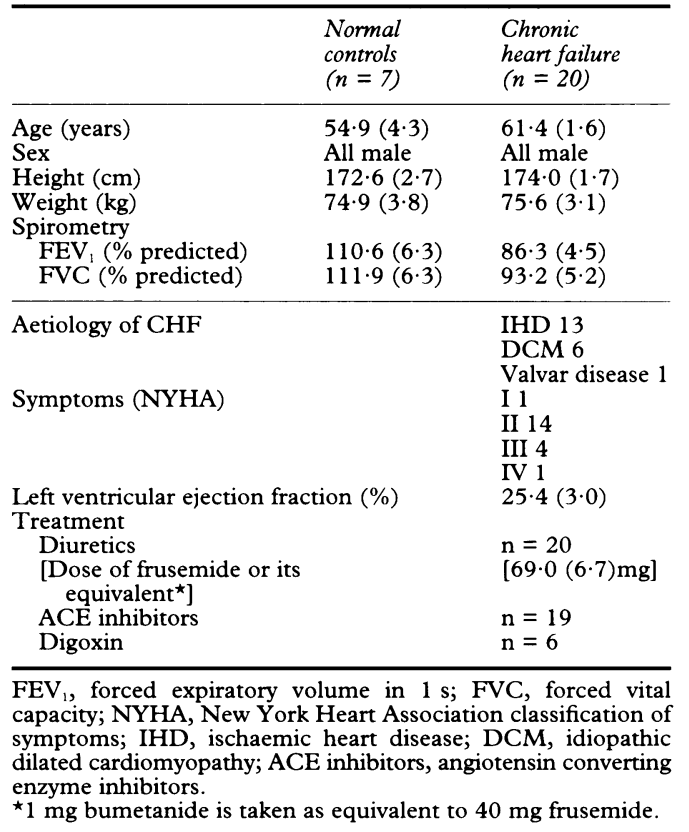

had their right quadriceps muscle strength assessed. ${ }^{11}$ They were seated within a rigid framework and were asked to produce maximum right knee extension against a stirrup attached to a strain gauge. This was accepted as the maximum isometric force produced when a superadded stimulus applied through saline pad electrodes to the right quadriceps of $1 \mathrm{~ms}$ duration at $1 \mathrm{~Hz}$ failed to produce an additional twitch at the plateau of the contraction. The strain gauge had previously been calibrated against known masses. The maximum isometric force was expressed in $\mathrm{N}$ (newtons).

\section{CARDIOPULMONARY EXERCISE TESTING}

Cardiopulmonary exercise testing was performed in all the participants of the study to assess exercise capacity. All were exercised to exhaustion (peak respiratory exchange ratio, $\mathrm{R}>1 \cdot 1$ ) using the Bruce protocol, ${ }^{14}$ with the addition of a "Stage 0 " at $1.0 \mathrm{mph}$ and $5 \%$ gradient for the heart failure patients. Respiratory gas exchange analysis was carried out by means of a respiratory mass spectrometer (Amis 2000, Innovision) using the mixing box technique. ${ }^{15}$

\section{STUDIES OF REPRODUCIBILITY}

Repeat measurements of maximum inspiratory and expiratory mouth pressures were made in three controls and three heart failure patients on a separate day to evaluate the reproducibility of the test.
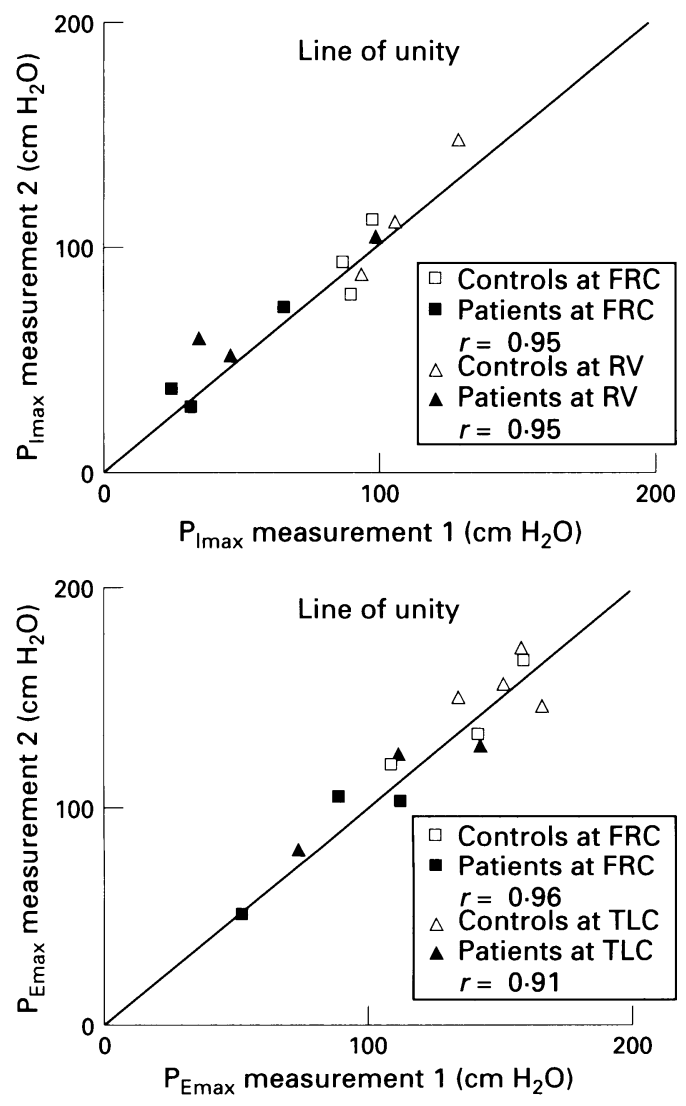

Figure 1 Reproducibility of maximum inspiratory $\left(\boldsymbol{P}_{\text {Imax }}\right)$ and expiratory $\left(\boldsymbol{P}_{\text {Emax }}\right)$ mouth pressures in three controls and three patients with chronic heart failure. 
Table 2 Results of maximum oxygen consumption and respiratory and right quadriceps muscle strength. Values are means (SEM).

\begin{tabular}{llll}
\hline & $\begin{array}{l}\text { Controls } \\
(n=7)\end{array}$ & $\begin{array}{l}\text { Chronic heart failure } \\
(n=20)\end{array}$ & P value \\
\hline $\begin{array}{l}\text { Maximum oxygen consumption } \\
(\mathrm{ml} / \mathrm{min} / \mathrm{kg})\end{array}$ & $36.2(3.5)$ & $17.3(1.5)$ & 0.001 \\
$\mathrm{P}_{\mathrm{Imax}}\left(\mathrm{cm} \mathrm{H} \mathrm{H}_{2} \mathrm{O}\right)$ & & & \\
$\quad$ FRC & $85.6(9.6)$ & $59.7(6.3)$ & 0.045 \\
RV & $89.3(13.0)$ & $77.3(6.6)$ & 0.44 \\
$\mathrm{P}_{\text {Emax }}\left(\mathrm{cm} \mathrm{H}_{2} \mathrm{O}\right)$ & & & \\
$\quad$ FRC & $134.6(9.1)$ & $94.8(6.2)$ & 0.004 \\
$\quad$ TLC & $160.7(13.0)$ & $121.7(8.5)$ & 0.028 \\
Right quadriceps strength $(\mathrm{N})$ & $446.2(28)$ & $308.5(22)$ & 0.001 \\
\hline
\end{tabular}

Values expressed as mean \pm SEM. P values obtained using Student's $t$ test (see text).

\section{STATISTICAL ANALYSIS}

The results are presented as means (SEM). Student's $t$ test was used to assess the significance of results. The Mann-Whitney U test was also applied to determine any appreciable difference in values of significance using a non-parametric statistical method. The relationship between variables was assessed using linear regression analysis. $P<0.05$ was considered significant.

\section{Results}

As shown in table 1, the means for age, height, and weight of controls and heart failure patients did not differ significantly. The correlation between repeated measurements of $P_{I \max }$ and $P_{E \max }$ in six subjects is shown in fig 1 with $r>0.9$ for both maximum inspiratory and maximum expiratory mouth pressures. The coefficients of variation for $P_{I \max }$ at
FRC and RV were $6 \cdot 7 \%$ and $5 \cdot 7 \%$ respectively. For $P_{\text {Emax }}$ at FRC and TLC, the values were $5.5 \%$ and $6 \cdot 7 \%$.

Results of maximum oxygen consumption, respiratory strength, and right quadriceps muscle strength in the heart failure patients and healthy controls are presented in table 2 . Patients with heart failure due to ischaemic heart disease did not have evidence of myocardial ischaemia and were not limited by angina during cardiopulmonary exercise testing, although two of these patients were on a nitrate medication and a third on diltiazem and a nitrate. $P_{I \max }$ at FRC was significantly reduced in heart failure patients, as was $P_{\text {Imax }}$ at $\mathrm{RV}$ although the latter did not reach statistical significance. There was also a significant reduction in $P_{E \max }$ both at FRC and at TLC. The quadriceps muscle was weaker in the heart failure patients. The significance of results did not differ when the Mann-Whitney $\mathrm{U}$ test was applied $\left(\mathrm{P}_{\mathrm{Imax}}\right.$ at $\mathrm{FRC}, \mathrm{P}=0.033$; $P_{I \max }$ at $R V, P=0.36 ; P_{E \max }$ at FRC, $P=$ $0.003 ; P_{\text {Emax }}$ at TLC, $P=0.014$ ).

When maximum oxygen consumption was correlated with maximum mouth pressures in the heart failure patients, $P_{I \max }$ at both FRC and RV correlated significantly as shown in fig $2(r=0.59, \mathrm{P}=0.006$, and $r=0.45, \mathrm{P}=$ 0.048 respectively). On the other hand, $P_{E \max }$ at FRC and TLC was not correlated with maximum oxygen consumption. As seen in fig 3 , there was no significant correlation between $P_{I \max }$ or $P_{E \max }$ and right quadriceps strength.

\section{Discussion}

This study shows that there is respiratory
Figure 2 The relation between maximum oxygen consumption and maximum inspiratory pressure $\left(P_{\text {Imax }}\right)$ is shown on the top two plots and maximum expiratory pressure $\left(P_{\text {Emax }}\right)$ on the bottom two plots.

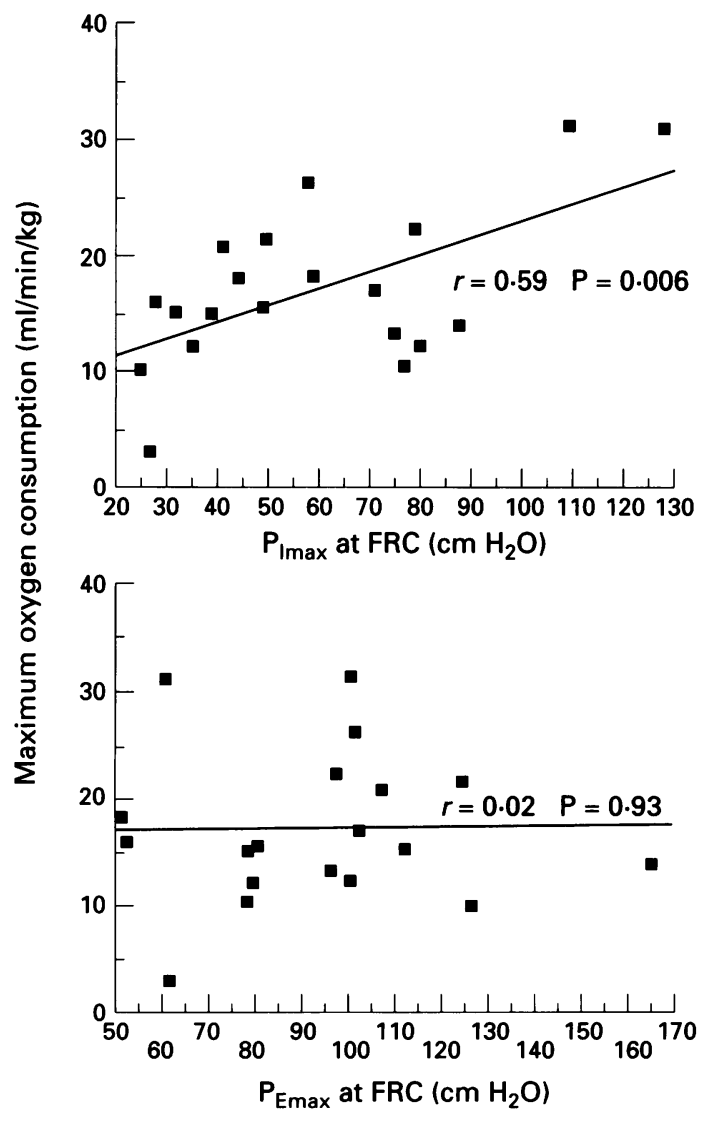


Figure 3 The plots above show that there is no correlation between respiratory muscle strength and right quadriceps strength in chronic heart failure.
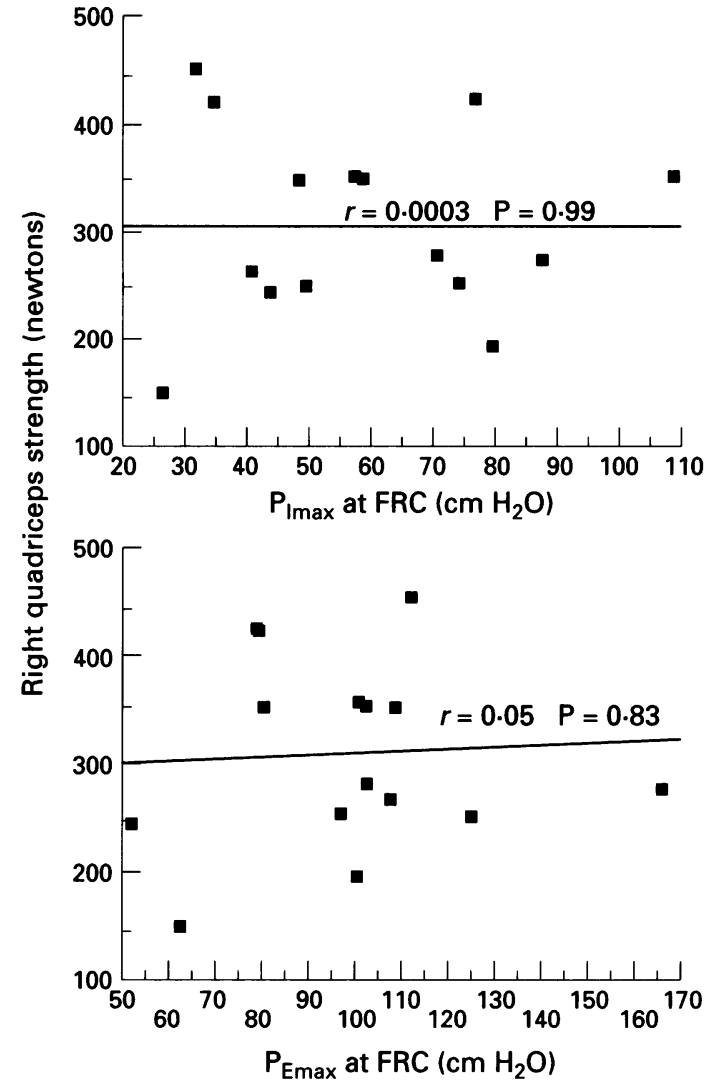

muscle weakness in patients with chronic heart failure. The significant reduction in $\mathrm{P}_{\mathrm{Imax}}$ at FRC and $P_{\text {Emax }}$ at FRC and TLC in heart failure patients is compatible with the findings of some investigators ${ }^{13}$ although others ${ }^{216}$ could not show a significant reduction in $P_{\text {Emax }}$. This may be because of the smaller size of their study population. Although not statistically significant, a reduction in $P_{\operatorname{Imax}}$ at $R V$ was also seen in heart failure patients in our study. A larger more severely affected group of patients may be needed to show this reduction in $P_{I \max }$ at $R V$ more convincingly. Respiratory muscle fatigue is, among other things, dependent on the amount of energy expended during breathing. ${ }^{17}$ Even if the work of breathing is the same in patients with chronic heart failure compared with normal individuals, a greater fraction of a relatively reduced maximum strength is needed in order to breathe. This increases the energy demands and hence the tendency to fatigue. ${ }^{17}$ The work of breathing in heart failure is in fact not the same as in normal subjects, considering that these patients may have an obstructive, restrictive, or mixed airways abnormality ${ }^{18-24}$ and indeed breathe excessively for a given workload or rate of carbon dioxide production. Incidentally, our patients showed a reduction in both $\mathrm{FEV}_{1}$ and FVC. Furthermore, some patients may have interstitial lung changes due to chronic pulmonary venous hypertension. ${ }^{25-27}$ Normally, there is an optimal frequency of breathing and tidal volume, resulting in minimum work. ${ }^{28}$ In heart failure patients, it has been shown by some investigators that during exercise the onset of dypsnoea is characterised by a sudden increase in the frequency of breathing, with little change in
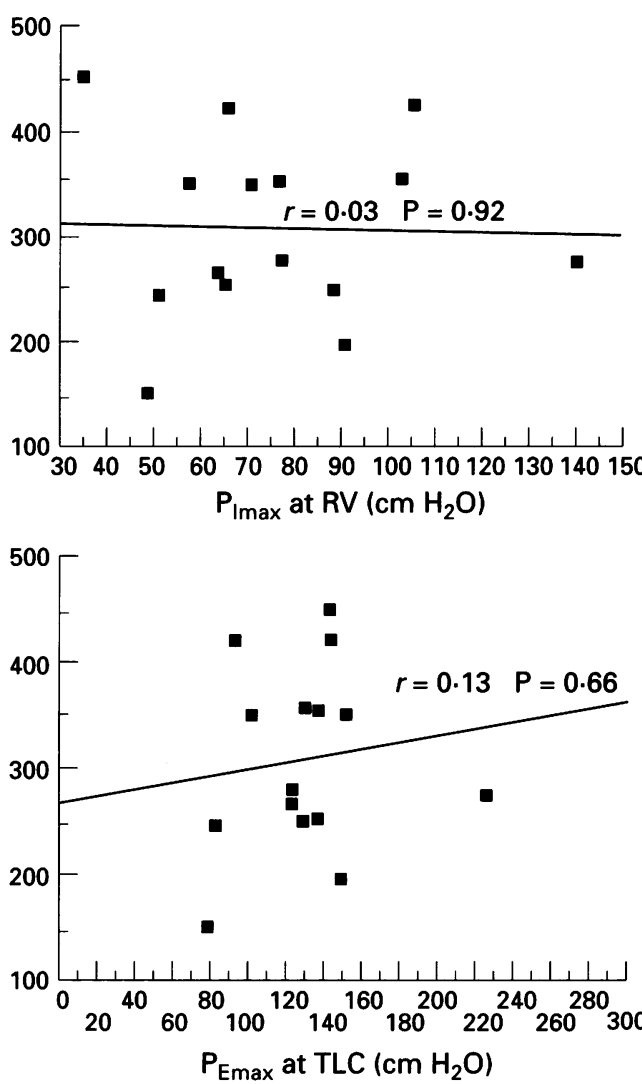

tidal volume. ${ }^{29}$ All these observed abnormalities in chronic heart failure serve only to increase the work of breathing and make respiratory muscle strength even more important as a contributory cause of breathlessness and exercise intolerance. In addition to showing underperfusion of the respiratory muscles during exercise, ${ }^{7}$ Mancini et $a l^{3}$ have found that there is increased diaphragmatic work in heart failure patients. Interestingly, they could not establish respiratory muscle fatigue in their patients after maximal bicycle exercise, although the three to five minute time delay in recording the measurements after exercise may have made muscle fatigue less easily detectable.

From our study, inspiratory muscle strength is seen to be a determinant of maximum oxygen consumption in heart failure patients. This is in agreement with the findings of Nishimura et al. ${ }^{16}$ The inspiratory muscles consist of the diaphragm and the external intercostal and accessory muscles. The diaphragm is the most important of these, since breathing with intercostal or accessory muscles does not normally occur. ${ }^{17}$ Expiration, by contrast, is predominantly due to the passive relaxation of the diaphragm, although during heavy breathing the abdominal recti and internal intercostals are involved in producing rapid expiration. ${ }^{30}$ Thus, despite the reduced maximum expiratory mouth pressures seen in the heart failure patients in our study, it is not surprising to see that only inspiratory muscle strength measurements correlated significantly with maximum oxygen consumption. That there was a significant correlation further suggests that the inspiratory muscles, in particular the diaphragm, are probably important in determining the exercise tolerance in these patients. 
The cause of respiratory muscle weakness is not known. It may be due to underperfusion and a reduced flow of nutrients to the muscles because of lower cardiac output or peripheral vasoconstriction, ${ }^{31}$ or it may be related to the neuroendocrine abnormalities seen in heart failure, such as increased catecholamine level ${ }^{32}$ and insulin resistance, ${ }^{33} 34$ leading to changes in diaphragmatic muscle structure or function. Inactivity and subsequent deconditioning are considered important causes of skeletal myopathy in chronic heart failure, but whether this is applicable to muscles responsible for such constant work and rhythmicity as breathing is open to debate. Part of the process of inspiration also involves the downward displacement of the abdominal viscera. Fluid engorged viscera such as the liver may act as a mechanical impediment to this and cause a reduction in the efficiency of inspiratory muscle activity. None of our patients, however, had obvious peripheral oedema during the study.

It is interesting that there was a lack of correlation between respiratory muscle strength and locomotor muscle strength. This suggests that the magnitude and time course of muscle weakness involving the respiratory and locomotor muscles may differ in individual patients. It has been shown that physical training is beneficial in heart failure and improves exercise capacity as well as the ventilatory response to exercise. ${ }^{35}$ If respiratory and skeletal myopathy do not follow the same time course of the disease process and if they are not affected equally, then the implication is that treatments such as training may need to include inspiratory muscle endurance exercises. ${ }^{36}{ }^{37}$ It may be necessary to "rehabilitate" each particular muscle group, including respiratory muscles, to improve exercise tolerance and relieve the symptoms of both breathlessness and muscle fatigue.

In conclusion, respiratory muscle weakness is seen in patients with chronic heart failure. Inspiratory muscle strength is a determinant of maximum oxygen consumption and exercise tolerance. Respiratory muscles and skeletal muscles appear to be discordantly affected in this condition. Further research is required to investigate the reasons for this discordance and to test the hypothesis that treatments with the specific aim of improving respiratory muscle function may be beneficial to those in whom respiratory muscle weakness is shown to be a factor in symptomatic limitation of exercise.

TCP is supported by a junior research fellowship from the British Heart Foundation. AJSC is supported by the Viscount Royston Trust and the British Heart Foundation.

1 Hammond MD, Bauer KA, Sharp JT, Rocha RD. Respiratory muscle strength in congestive heart failure. Respiratory muscle stre
Chest 1990;98:1091-4.

2 McParland C, Krishnan B, Wang Y, Gallagher CG. Inspiratory muscle weakness and dyspnea in chronic Inspiratory muscle weakness and dyspnea in ch

3 Mancini DM, Henson D, LaManca J, Levine $S$. Respiratory muscle function and dyspnea in patients with chronic congestive heart failure. Circulation 1992; 86:909-18

4 Mancini DM, Lamanca J, Henson D. The relation of respiratory muscle function to dyspnea in patients with heart failure. Heart Failure 1992;8:183-9.

5 Weiser PC, Henson D. Mechanisms of exertional dyspnea. Heart Failure 1992;8:202-9.

6 Lindsay DC, Lovegrove CA, Dunn MJ, Bennett JG Pepper JR, Yacoub MH, et al. Histological abnormalities of diaphragmatic muscle may contribute to dyspnea in heart failure. Circulation 1992;86(suppl I):1-514.

7 Mancini DM, Ferraro N, Nazzaro D, Chance B, Wilson JR. Respiratory muscle deoxygenation during exercise in patients with heart failure demonstrated with nearinfrared spectroscopy. $\mathcal{F}$ Am Coll Cardiol 1991;18:492-8.

8 Massie BM, Conway M, Yonge R, Frostick S, Ledingham J. Skeletal muscle metabolism during exercise under ischemic conditions in congestive cardiac failure. Circulation 1988;78:320-6.

9 Minotti JR, Christoph I, Oka R, Weiner MW, Wells L, Massie BM. Impaired skeletal muscle function in patients with congestive heart failure. Relationship to patients with congestive heart failure. Relationship to
systemic exercise performance. $\mathcal{f}$ Clin Invest 1991;88: systemic $2077-82$.

10 Wilson JR, Mancini DM, Dunkman WR. Exertional fatigue due to skeletal muscle dysfunction in patient with heart failure. Circulation 1993;87:470-5.

11 Buller N, Jones D, Poole-Wilson PA. Direct measuremen of skeletal muscle fatigue in patients with chronic hear failure. Br Heart $\mathcal{F}$ 1991;65:20-4.

12 Tada H, Kato H, Misawa T, Sasaki F, Hayashi S, Takahashi $\mathrm{H}$, et al. ${ }^{31} \mathrm{P}$-nuclear magnetic resonance evidence of abnormal skeletal muscle metabolism in patients with chronic lung disease and congestive heart failure. Eur Respir F 1992;5:163-9.

13 Black LF, Hyatt RE. Maximal respiratory pressures: normal values and relationships to age and sex. Am Rev Respir Dis 1969;99:696-702.

14 Bruce RA, Blackman JR, Jones JW. Exercise testing in adult normal subjects and cardiac patients. Pediatrics 1963;32:742-55.

15 Davies N, Denison DM. The measurement of metabolic gas exchange and minute ventilation by mass spectrometry alone. Respir Physiol 1979;36:261-7.

16 Nishimura $Y$, Maeda $H$, Tanaka $K$, Nakamura $H$ Hashimoto Y, Yokoyama M. Respiratory muscle strength and haemodynamics in chronic heart failure. Chest 1994;105:355-9.

17 Roussos C, Macklem PT. The respiratory muscles. $N$ Engl f Med 1982;307:786-97.

18 Ries AL, Gregoratos G, Friedman PJ, Clausen JL. Pulmonary function tests in the detection of left heart Pulmonary function tests in the detection of left heart failure: correlation with pulmonary
sure. Respiration 1986;49:241-50.

19 Hosenpud JD, Stibolt TA, Atwal K, Shelley D. Abnormal pulmonary function specifically related to congestive heart failure: comparison of patients before and after cardiac transplantation. Am f Med 1990;88:493-6.

20 Wright RS, Levine MS, Bellamy PE, Simmons MS, Batra $P$, Stevenson LW, et al. Ventilatory and diffusion abnormalities in potential heart transplant recipients. Ches 1990;98:816-20.

21 Naum C, Sciurba FC, Rogers RM. Pulmonary function abnormalities in chronic severe cardiomyopathy precedingcardiac transplantation. Am Rev Respir Dis 1992;145: 1334-8.

22 Ravenscraft SA, Gross CR, Kubo SH, Olivari MT, Shumway SJ, Bolman RE, et al. Pulmonary function after successful heart transplantation. Chest 1993;103: after 8 .

23 Faggiano P, Lombardi C, Sorgato A, Ghizzoni G, Spedini C, Rusconi C. Pulmonary function tests in patients with congestive heart failure: effects of medical therapy. Cardiology 1993;83:30-5.

24 Petermann W, Barth J, Entzian P. Heart function and airway obstruction. Int $\mathcal{F}$ Cardiol 1987;17:207-9.

25 Parker F, Weiss S. The nature and significance of the structural changes in the lungs in mitral stenosis. $A m$ Pathol 1936;12:573-98.

26 Heath D, Edwards FR. Histological changes in the lung in diseases associated with pulmonary venous hypertension. Br $\mathcal{F}$ Dis Chest 1959;53:8-18.

27 Kay JM, Edwards FR. Ultrastructure of the alveolar capillary wall in mitral stenosis. $\mathcal{F}$ Pathol 1973;111: 239-45.

28 Otis $\mathrm{AB}$, Fenn WO, Rahn $\mathrm{H}$. Mechanics of breathing in man. $\mathcal{F}$ Appl Physiol 1950;2:592-607.

29 Yokoyama H, Sato H, Hori M, Takeda H, Kamada T. A characteristic change in ventilation mode during exertional dyspnea in patients with chronic heart failure. Chest 1994;106:1007-13.

30 Guyton AC. Textbook of medical physiology, 8th ed Philadelphia: WB Saunders, 1991

31 Levine TB, Levine AB. Regional blood flow supply and demand in heart failure. Am Heart $\mathcal{F}$ 1990;120:1547-51.

32 Packer $M$. The neurohormonal hypothesis: a theory to explain the mechanism of disease progression in heart failure. $\mathcal{A} \mathrm{Am}$ Coll Cardiol 1992;20:248-54.

33 Coats AJS, Clark AL, Piepoli M, Volterrani M, PooleWilson PA. Symptoms and quality of life in heart failure: the muscle hypothesis. $B r$ Heart $f$ 1994;72(suppl): the m36-9.

34 Swan JW, Walton C, Godsland IF, Clark AL, Coats AJS Oliver MF. Relationship of insulin resistance to severity and aetiology of chronic heart failure. Circulation 1994; and (suppl):I-174.

35 Coats AJS, Adamopoulos S, Radaelli A, McCance A, Meyer T, Bernardi L, et al. Controlled trial of physical training

36 Leith DE, Bradley $M$. Ventilatory muscle strength and endurance training. $\mathcal{F}$ Appl Physiol 1976;41:508-16.

37 Mancini DM, Henson D, La Manca J, Donchez L, Levine $\mathrm{S}$. Benefit of selective respiratory muscle training on exercise capacity in patients with chronic congestive heart failure. Circulation 1995;91:320-9. 